PRAXIs. ReVISTA DE Filosofía № 73

ENERO - JUNIO 2016

http://dx.doi.org/10.15359/praxis.73.5

ISSN: 1409-309X

\title{
MÁS ALLÁ DEL PRINCIPIALISMO: HACIA UNA RECONCEPTUALIZACIÓN DE LA BIOÉTICA
}

\section{BEYOND PRINCIPLISM:TOWARDS A RECONCEPTUALIZATION OF BIOETHICS}

\author{
Wilmer Casasola Rivera ${ }^{1}$ \\ Instituto tecnológico de Costa Rica
}

Recibido: 23 de diciembre, 2015 / Aceptado: 8 de marzo, 2016

Resumen: El artículo aborda el problema epistemológico del reduccionismo en bioética, esto es, el principialismo. Critica la carencia de rigurosidad conceptual de los cuatros principios y la negligencia académica de aceptar pasivamente estos principios sin mayor interpretación al punto de considerar la bioética producto de cuatro principios rectores. A este reduccionismo bioética se le llama aquí el dogma de la bioética. El artículo discute que para ir más allá del principialismo se debe antes realizar una reconceptualización de la bioética.

Palabras clave: bioética, principialismo, ética, moral, hermenéutica, epistemología, marco epistémico, marco axiológico, reduccionismo, dogma, comités de bioética, CCSS

Summary: The article brings on board the epistemological problem of reductionism in bioethics, this is, the principlism. It criticizes the lack of conceptual thoroughness of the four principles and the academic negligence of passively accepting them with no further interpretation and considering bioethics a product of these four main principles.

This reductionism in bioethics is called the dogma of bioethics. The article discusses that to be able to go beyond principlism it is imperative a reconceptualization of bioethics as a first step.

1 Máster en Neuropsicología, Máster en Bioética, Licenciado en Filosofía. Docente de la Escuela de Ciencias Sociales del Instituto Tecnológico de Costa Rica.

Este artículo se escribe gracias al patrocinio del INIF (Instituto de Investigaciones Filosóficas) de la Universidad de Costa Rica. Proyecto de Investigación 743-B3-345. Correspondencia con el autor: philoskaigraphos@gmail.com 
Wilmer Casasola Rivera

Keywords: bioethics, principlism, ethics, moral, hermeneutics, epistemology, epistemological frame, axiological frame, reductionism, dogma, bioethics committees, CCSS

\section{Introducción}

Criticar una teoría ética no tiene un efecto negativo siempre que se intente mejorar la experiencia moral. El principialismo es una postura en el campo de la ética médica que se ha extendido al campo de la bioética. Decir que el principialismo es la ética de la bioética, no solo es extraño, puesto que la bioética debería ser ella misma una ética aplicada, sino que es un juicio excesivamente parcializado porque descarta otras posturas éticas, clásicas o contemporáneas.

Se ha tomado como dogma hablar de los cuatro principios de la bioética, al punto de que los comités de bioética se organizan en torno a esta idea. Sin embargo, la bioética tiene que salir de este reduccionismo ingenuo porque los cuatro principios no ofrecen en sí mismos una base epistemológica para tomar decisiones, sino que están sujetos a interpretaciones de acuerdo con marcos axiológicos diversos. ¿Cuáles son los criterios epistemológicos que deben estar presentes en una teoría ética para que cuente con objetividad? ¿Cuál es el criterio para determinar la objetividad de un punto de vista ético a la hora de tomar decisiones éticas? La bioética debe construir esta objetivad, pero no lo puede lograr en los regazos del principialismo.

El objetivo principal de este artículo consiste en discutir las implicaciones del reduccionismo en bioética. Se denomina aquí reduccionismo bioético a la costumbre de asumir el principialismo ordinario como el marco de referencia que legitima la bioética como profesión. Bioética principialista es aquella que asume cuatro principios cardinales como fundamento de toda ética. A este reduccionismo se le llama aquí el dogma de la bioética. El problema base que orienta este apartado se enfoca en los criterios epistemológicos y hermenéuticos que subyacen a la hora asumir un concepto. Cuando se habla de forma categórica de los cuatro principios de la bioética sin reparar en las bases epistemológicas que sustentan tal afirmación, estamos en presencia de una carencia de rigurosidad conceptual. En este sentido, la carencia de rigurosidad conceptual es el problema que se expone en este artículo. 
El trabajo es la continuidad de tres artículos anteriores. En este artículo se aborda cinco temas y un apartado a modo de conclusión. El primero ofrece una breve exposición de lo que serían los cuatro principios usualmente llamados principios de la bioética. El segundo apartado aborda el tema de la rigurosidad conceptual de los cuatros principios. Discute el problema concreto de cómo la carencia de rigurosidad conceptual tiene implicaciones éticas. El apartado procura confrontar la negligencia profesional que no reflexiona sobre los conceptos que se asumen diariamente. Para tal fin, se enfoca fundamentalmente en dos principios: autonomía y beneficencia, desde donde desarrolla el análisis sobre la carencia de rigurosidad conceptual de los principios que orientan la bioética clínica. El apartado tercero discute lo que se entiende aquí por marco axiológico y marco epistémico. Un marco axiológico es el conjunto de valores morales que una persona asume como intrínsecamente buenos o correctos, en tanto que un marco epistémico es un conocimiento racionalmente bien sustentado que proporciona criterios de objetividad para valorar las creencias y opiniones con las que nos referimos a la realidad. El apartado cuarto ofrece una breve reflexión sobre el principialismo como dogma, el dogma de la bioética. En el quinto apartado se discute el problema epistemológico del concepto de bioética. Se discute la inserción de la hermenéutica en la bioética como recurso filosófico para la interpretación de los conceptos, así como la importancia de la responsabilidad académica a la hora de interpretarlos. Para ir más allá del principialismo se debe antes realizar una reconceptualización de la bioética, y por tanto realizar un giro bioético. Finalmente, un apartado a modo de conclusión intitulado una tarea por delante, en el que si discute lo que aún falta por realizar en bioética como campo profesional y académico.

\section{Los "cuatro principios de la bioética"}

Con frecuencia se habla en los manuales de bioética de "los principios de la bioética". Esta idea se ha generalizado en la medida que se ha escolarizado en los medios profesionales la divulgación de cierta pedagogía bioética que establece que existen cuatro principios rectores.

Si bien es cierto que los cuatro principios son abundantemente conocidos en los ámbitos académicos, se ofrece a continuación una breve 
descripción de estos principios, tomando como punto de referencia los Principios de ética biomédica. Se aclara que este apartado no persigue ofrecer un estudio detallado sobre el libro Principios de ética biomédica de Beauchamp y Childress, sino rescatar algunas ideas representativas de los conceptos autonomía, justicia, beneficencia y no maleficencia. Existe abundante literatura al respecto sobre estos autores y el principialismo, se para criticarlos, sea para defenderlos.

Por otra parte, aunque este primer apartado tiene como objetivo básico describir los cuatros principios, se intercalan interpretaciones a la luz de algunas posiciones teóricas existentes, así como la propia crítica.

\section{a) Autonomía}

El principio de autonomía supone el respeto hacia los individuos en cuanto a sus decisiones morales. En palabras de Beauchamp y Childress (1999), se trata del respecto que merece un agente autónomo en cuanto a "su derecho a tener opiniones propias, a elegir y a realizar acciones basadas tanto en sus valores como en sus creencias personales". (117). Se trata de cierta libertad que tienen los individuos para actuar de acuerdo con su propia voluntad, la cual implica respetar sus intereses, deseos y creencias particulares.

En el Informe Belmont ${ }^{2}$, documento que da pie a la ética biomédica, se enfatiza en la idea de que "una persona autónoma es un individuo capaz de deliberar acerca de sus metas y de actuar bajo la guía de tal deliberación." Sin embargo, cuando los individuos presentan "autonomía disminuida", un concepto clave en la epistemología de la bioética, son otros mecanismos éticos los que se tienen que tomar en cuenta a la hora de realizar un procedimiento clínico, especialmente cuando se trata de investigación biomédica o científica.

Precisamente en eso consiste la autonomía en este contexto: una capacidad racional de deliberar sobre asuntos que afectan la propia moralidad, que afectan la propia vida. Cuando existe coacción o persuasión moral sobre otra persona, no existe autonomía, ni se le otorga autonomía a esa persona. Sobre este punto es importante tomar en cuenta el problema ético, o bien,

2 El documento citado: Informe Belmont Principios y guías éticos para la protección de los sujetos humanos de investigación (2003). Centro de Documentación de Bioética. Universidad de Navarra. 
el problema bioético de la autonomía disminuida, especialmente al momento de tomar decisiones sobre asuntos que afectan física y moralmente. Buchanan y Brock (2009, p. 49) advierten que "cuando las personas son incapaces de tomar por sí mismas una decisión y otros deben decidir en su nombre, el valor instrumental de la autodeterminación aún puede respetarse indirectamente si se aplican principios orientadores que exijan a los sustitutos buscar las decisiones que más se conformen a los objetivos y valores de la persona cuando era capaz". Nótese que principio de autonomía va más allá de un asunto inmediatista, del aquí y el ahora, sino que implica un verdadero respecto por los valores, las creencias, los temores de las personas cuando sus facultades aún no habían cesado y que deben respetarse cuando han disminuido o desaparecido del todo.

Autonomía, en este contexto, es la capacidad que tienen los individuos de tomar decisiones por su propia cuenta de acuerdo con los criterios de su propia moralidad, sin que ningún agente externo intente coaccionarlo para que piense diferente. La voluntad moral, política, religiosa, cultural debe respetarse bajo cualquier circunstancia. Pero esto es falso. Nadie, menos aún una persona enferma, tiene tanta autonomía para poder dirigir su vida sin que exista irrespeto a través de un discurso de poder paternalista en el ámbito clínico.

\section{b) No maleficencia}

Este principio se expresa en términos deontológicos: no debes. Su tesis básica es simplemente "no se debe causar daño o mal". (Beauchamp y Childress, 1999, p. 181). Este principio supone los términos daño e injuria, que de alguna forma implican una serie de imperativos como no matarás, no causarás dolor, no incapacitarás a otros, no ofenderás, etc., según los autores citados. Este principio tiene su origen en el aforismo latino atribuido a Hipócrates primum non nocere.

No se puede perder de vista que el principio de no hacer daño es ambiguo, toda vez que la intervención médica supone siempre algún riesgo de provocar daño. El primum non nocere supone siempre la posibilidad de causar algún daño, lo cual no significa que se deba detener la práctica clínica. Es lo 
que Lifshitz llama provocar una "parálisis operativa" (2002). La discusión sobre cómo se debe proceder, es un asunto de ética prima facie.

Lo que sí sabemos es que el primum non nocere, tanto en ética médica, ética de la investigación o más globalmente, en bioética, nos indica imperativamente que "no se debe causar perjuicio o daño al usuario o paciente" (Casado y Seoane, 2008, p. 110). Sin embargo, hoy sabemos que el abuso clínico ha sido uno de los más representativos en el campo de la investigación científica y médica. Y se debe tomar en cuenta que abuso va más allá de abuso directo; el abuso también es indirecto, como cuando existen investigaciones científicas poco serias. Son muchos miles de millones invertidos anualmente en investigación científica. Los periodistas Langbein y Ehgartner realizaron una rigurosa investigación (2002, p. 234) sobre los negocios oscuros de la medicina y la industria farmacéutica. Sostienen que las investigaciones "al ser de origen privado la mayor parte del dinero invertido, hay urgencias por ver resultados. Se abusa de la legislación de patentes para demorar o impedir la comunicación científica. Los resultados provisionales se anuncian a los medios de comunicación como buenos, de forma acrítica, con el fin de atraer más inversionistas". El concepto de no maleficencia va más allá de una pobre interpretación a la luz de un mandato divino o irreflexivamente protocolar.

¿Qué es la no-maleficencia entonces? Simplemente la disposición moral o ética de no causar daño intencionalmente. Daño siempre habremos de hacer. Usar este ordenador o computadora en la que escribo en este preciso momento me hace partícipe de un daño ecológico; imprimir este artículo, te hace partícipe de otro daño ecológico... El simple hecho de haber nacido nos hace partícipes de un daño ecológico... Pero el punto central del principio es el no causar daño intencionalmente. Esto es, cuando existe deliberadamente una acción encaminada a promover y causar daño a una persona con un grado de autonomía disminuida o nula.

\section{c) Beneficencia}

Se entiende por principio de beneficencia "la obligación moral de actuar en beneficio de otros" (Beauchamp y Childress, 1999, p. 246). En el campo de la salud, se trata de una obligación profesional de procurar el bienestar de los pacientes bajo cualquier circunstancia. Se trata de una acción 
objetiva, por lo que los intereses particulares no pueden estar presentes a la hora de aplicar este principio.

Sin embargo, históricamente este principio se ha asociado con el paternalismo precisamente porque el criterio de objetividad consiste en creer o estar en la facultad de saber lo que redunda en beneficio del paciente, desestimando su autonomía.

Como se trata de una actitud que intenta hacer el bien o ayudar a los demás a satisfacer sus necesidades, cabe siempre la posibilidad de violentar la autonomía misma del paciente o persona a quien se asiste en nombre de un supuesto beneficio. No se debe perder de vista que el principio de beneficio exige no dañar, y no dañar demanda respetar la autonomía del paciente. Por tal motivo, existe beneficencia cuando las personas involucradas voluntariamente lo pidan o lo acepten de aquella persona que pretende beneficiar. Como aclaran Casado y Seoane (2008, p. 135), "el principio de beneficencia es un deber positivo o de promoción, forma parte de la ética de máximos y no se puede exigir coactivamente".

La beneficencia es, entonces, una pauta ética profesional que nos obliga a procurar bienestar hacia la persona que depende, directa o indirectamente, de nuestra profesión.

\section{d) Justicia}

Existen varias concepciones materiales de justicia. De acuerdo con la concepción de justicia que se trabaje, una persona puede recibir un trato diferente. Al respecto afirman Beauchamp y Childress (1999) que "una tesis moral plausible es que cada uno de esto principios materiales identifica una obligación prima facie cuyo peso no puede evaluarse independientemente de las circunstancias particulares o de las esferas en las que son especialmente aplicables" (p. 315).

En el contexto clínico, el principio de justicia se relaciona con la norma ética de dar a cada quien lo que necesita. Esto supone una adecuada distribución de los recursos materiales existentes así como un trato no preferencial a cada uno de los pacientes, es decir, igual justicia en el trato. Se parte de la idea del derecho que tiene el paciente a la salud y el deber de 
profesionales de la salud de devolverla de acuerdo con la misión que tiene el Estado para estos fines.

También se habla del principio de justicia como una obligación estatal. De acuerdo con Roa (1998, p. 166), el principio de justicia no solamente "involucra al médico y al paciente, sino a la sociedad o al Estado, cuya obligación es procurar los recursos suficientes para que todos tengan acceso fácil a la salud, cualquiera sea su situación social o económica”. Roa señala además que este principio "justifica la necesidad de destinar dinero para adquirir tecnología de avanzada y para facilitar la investigación científica médica". (1998, p. 167).

El concepto de justicia no es fácil de abordar. Desde la antigüedad se ha intentado definir lo que es la justicia hasta nuestros días. En el campo de la ética, y más recientemente de la bioética, el concepto de justicia no tiene suficiente claridad. Y cuando parece tenerla, hay que caer en cuenta que se trata de un enunciado muy idealizado, un derroche de candidez filosófica. Como en los otros principios, el marco axiológico, o bien, el marco de referencia teórico con el que se mire (o se quiera mirar) la realidad, es determinante para comprender el concepto de justicia.

\section{Rigurosidad conceptual de los cuatro principios}

¿Qué tiene de mal la bioética principialista? Posiblemente para muchos, nada. Para otros sin embargo, sí. Siendo objetivos, no se le puede restar méritos a la teoría ética, especialmente por el alcance práctico que ha tenido. Sin embargo, la puntual crítica al principialismo radica en dos puntos clave: no puede reducirse la experiencia moral a cuatro principios rectores, y no existe claridad en el significado de cada principio sino que están sujetos a reinterpretaciones. La experiencia moral, tanto en la vida práctica cotidiana como en la profesional, es dinámicamente plástica. En el aspecto clínico, y específicamente en la investigación biomédica, los desafíos éticos son muchos y no los resuelven cuatro principios. Toda investigación científica requiere de un protocolo ético de investigación. Creer que desde cuatro principios se pueden establecer las bases de una investigación rigurosamente ética, es un cándido error. Ahora bien, si se considera que sí es viable, aparece en escena el segundo punto: la interpretación de los principios. Dos criterios, 
de muchos otros que pueden existir, de los que se parte para desarrollar una crítica a la bioética principialista.

Cuando se habla de rigurosidad conceptual no se puede perder de vista que el lenguaje orienta la acción moral. Lenguaje y pensamiento van unidos en toda acción moral. La rigurosidad conceptual es una exigencia epistemológica a la hora de crear principios que orientan la práctica moral. En ética, la rigurosidad conceptual es mayor.

El problema ético del principialismo, o bien, el problema de los principios que orientan la toma de decisiones éticas es un asunto bioético. Si estos principios orientan la toma de decisiones en cuanto decisiones correctas e incorrectas las bases que sustentan su marco axiológico deben ser consistentes desde un punto de vista epistémico.

Dentro de un comité de bioética el principialismo ha tomado raíces dogmatizantes. En lo que se sigue se discute el problema del principialismo en el contexto de los comités de bioética, haciendo especial referencia a comités de bioética en el contexto costarricense.

Ciertos manuales de divulgación bioética de la Caja Costarricense de Seguro Social (CCSS) parten de la tesis de que "la bioética es el estudio de la conducta humana en el área de las ciencias de la vida y del cuidado de la salud, en cuanto dicha conducta es examinada a la luz de principios y valores morales." (Comités de bioética en la CCSS). Esta definición, aunque no la señala el documento, proviene de la introducción de la Encyclopedia of Bioethics, de W. T. Reich.

Asumir una definición es asumir su validez desde diversos puntos de vista. Cuando se asume la validez de una definición le otorgamos estatuto epistemológico, moral, ético, científico, político, etc. Por tanto, existe cierto grado de compromiso y de responsabilidad sobre esa orientación teórica. Una definición representa el molde teórico con el que nos orientamos. Y nadie, en plenas facultades, asume un cuerpo teórico para orientarse mal.

Cuando hablamos de principios en ética nos referimos a aquellas pautas que orientan la práctica moral de una forma racionalmente aceptable. "Los principios son un tipo de normas, prescriben algo que tiene que hacerse, indicando una conducta que se debería adoptar." (López de la Vieja, 2002, p. 15). Como se aprecia, el punto de partida es básicamente el de todo proyecto de ética normativa: indicar cuál es la conducta correcta para actuar. 
Prescribir lo que tiene que hacerse es partir del supuesto de que hay unos principios incuestionables que no requieren de prueba porque ellos son el fundamento de toda discusión moral. Las personas están condicionadas a adoptar estos principios como garantes de haber alcanzado un verdadero desarrollo de su comportamiento moral, es decir, de haber alcanzado una verdadera madurez moral.

Esto tiene un contrapunto: el dogma moral, incluso el dogma conceptual. Cabe preguntar si los conceptos contenidos en el principialismo pueden orientar sin ambigüedad en los términos el análisis bioético correspondiente, si pueden orientar la práctica moral desde su propio enunciado.

Existen dos principios polémicos dentro del principialismo: autonomía y beneficencia. Por un lado tenemos el enunciado de que un agente moral autónomo es aquel que tiene la capacidad para deliberar sobre sus propios fines y decidir lo que redunda en su bien. Por otro lado tenemos el enunciado sobre el acto benevolente del médico, quien siempre obra en beneficio del paciente. Creer que siempre y en todo momento somos sujetos autónomos, así como creer que siempre y en todo momento el médico obra con buena intencionalidad ética es un cándido error. Y este es uno de los puntos lábiles del principialismo: una acción benevolente depende del marco racional con el que un sujeto percibe la realidad, y en el momento que percibe la realidad de su acción como moral o éticamente buena, entonces actúa sobre otros, desatendiendo la voluntad autónoma de otro individuo.

Si bien es cierto que algunos autores consideran al principialismo como un método adecuado para la toma de decisiones biomédicas, otros consideran que se trata de un reduccionismo que elimina la posibilidad de la interlocución ética adecuada. De ahí que algunos autores consideran que este enfoque basado en principios es insuficiente a la hora de abarcar la compleja realidad de los problemas que afronta (Pinto, 2010). Deliberar sobre asuntos éticos va más allá de teorías estáticas. Tiene que ver con cierto dinamismo racional, con cierta capacidad para discutir y deliberar para llegar a conclusiones que minimicen la probabilidad de error. Y desde luego, contar con fundamentos éticos en cuanto marcos de referencia, sin duda alguna contribuye a ubicar el análisis en un contexto más objetivo.

El problema del reduccionismo en el contexto bioético tiene que ver con nivelar un análisis técnico-clínico con un análisis ético. Por tal motivo, 
tanto en el campo de la filosofía como de las ciencias sociales en general, se procura ofrecer enfoques de análisis que articulen una "propuesta epistemológica más robusta desde el concepto de una bioética crítica." (Pinto, 2010, p. 73). Ahora bien, cuál es esta propuesta epistemológica y cuál es el marco teórico de una bioética crítica es lo que nos queda por determinar. Analizar los alcances y limitaciones de la bioética es una forma de iniciar, y una forma de salir de la cuna de la bioética de manual principialista.

El principialismo dentro de los comités de bioética puede verse desde diversos puntos de vista. Por un lado, podría creerse que se trata de una teoría que funciona en la práctica, y como tal, ha encontrado una legitimación en el quehacer profesional. Pero también puede estimarse que no es recomendable dejar en manos de cuatro principios la orientación ética en un comité de bioética o de ética, toda vez que la complejidad de los dilemas éticos y morales no se reduce a cuatro principios. Por eso es necesario el dinamismo racional, un dinamismo que tiene que ver con fomentar la racionalidad ética más que el dogma conceptual mecánico, mismo que se promueve en manuales de bioética.

Hace falta mayor cultura ética que fundamente el quehacer de la bioética con otras vertientes teóricas, dado que se entiende por bioética en nuestro medio, prácticamente una bioética médica. La racionalidad ética apuesta a este cambio, sin que ello quiera decir que un comité de bioética tenga que ser una extensión de un debate filosófico, pero al menos, que se discutan los dilemas éticos y morales en el lenguaje que corresponde. Y para esto se tienen que criticar las bases del principialismo ingenuo.

Hay criterios diversos en contra del principialismo. Para algunos autores el abordaje tiene que ser epistemológico, al punto de considerar la posibilidad de crear una nueva epistemología para la bioética. Se habla entonces de la necesidad de construir "un nuevo y más amplio estatuto epistemológico para la bioética” (Garrafa y Osório, 2009, p. 75). Nuevamente, construir este marco teórico es una tarea por realizar. Trazar la ruta es bueno. Ayudar a construirla, mejor. Pero ambos son importantes.

Un estatuto epistemológico, o marco epistémico, de alguna forma garantizaría una reelaboración metodológica de los fundamentos que sostienen una determinada teoría. Dado que no existe certeza ética, es necesario la elaboración de un marco epistémico en bioética que permita asegurar un 
revisión constante de los presupuestos conceptuales que legitiman un curso de acción moral. Esto es tarea de un dinamismo racional, de una racionalidad ética práctica que permita el análisis ético dinámico.

La idea de construir una epistemología para la bioética parte de la tesis de considerar al principialismo insuficiente. No existe duda alguna, a no ser que se comparta el dogma principialista, que los cuatro principios no pueden aplicarse a los casos concretos por ser demasiado generales (Requena, 2005). Esta generalidad se debe a que el lenguaje principialista es ambiguo en sus significaciones, lo que hace que la teoría sea poco fructífera en su aplicación al mundo de las situaciones concretas (Garrafa, Kottow, Saada, 2005). La generalidad redunda en un problema epistemológico a la hora de pretender aplicar los principios en contextos diversos, especialmente en los países del hemisferio centro y suramericano.

Podría pensarse apresuradamente que la generalidad de los principios es mejor. Sin embargo, esta generalidad tiene problemas filosóficos pocas veces advertida por personas que no son especialistas en esta materia. La ética tiene que abandonar esos grandes proyectos metafísicos elaborados desde el laboratorio de la razón pura, biológicamente imposible ${ }^{3}$, y concentrarse en orientaciones (si esa fuera su misión) específicas. Enfoques éticos puntuales no quiere decir enfoques éticos relativos. El criterio de objetividad es un requisito fundamental para cualquier enunciado ético.

La generalidad de los principios tiene muchas críticas. Tampoco se trata de crear deontologías para cada acto humano. Lo que se trata es de caer en cuenta que los conflictos de la vida humana no se pueden delimitar ni a un marco ético general ni a un marco ético muy particular. Hacer uso de una racionalidad ética constante permite, en alguna medida, vislumbrar la problemática.

Precisamente los problemas de una especificidad normativa se dejan ver en el reduccionismo principialista. Aplicar cuatro principios rectores y generales de forma mecánica y descontextualizada es una muestra de negligencia intelectual. Afirmar que no se puede llevar a cabo esta tarea es falso, porque habrá quién o quiénes lo harán o lo hacen. Lo que sí se puede

3 Algunos autores a quienes le he leído esta expresión son Zygmunt Bauman (Ética posmoderna, 2005); Mario Bunge (Seudociencia e ideología, 1985); Edgar Brightman (Una filosofía de los ideales, 1945) y José Ingenieros (Hacia una moral sin dogmas 1919). Sin embargo, con toda seguridad han de existir otros autores. En última instancia no importa en realidad quién o quiénes lo dijeron, pues con ello no se caería sino en una apelación a alguna autoridad, lo que verdaderamente importa es que la razón pura es biológicamente imposible... 
argumentar es, dada la complejidad moral del ser humano, que no se debe resumir en un sistema procedimental de cuatro principios abstractos, la forma como los seres humanos elaboran y resuelven sus propios conflictos morales, empresa atrevida, imposible e injusta para algunos (Pinto, 2010).

Esta manera mecánica, descontextualizada e irreflexiva puede darse en un comité de bioética, al considerar la bioética como la actividad protocolar que consiste en aplicar cuatro principios rectores a investigaciones biomédicas o científicas en general. Considerar que se puede contar con una clara orientación ética a partir de cuatro postulados es poco responsable. Los principios de la ética biomédica (lo que algunos llaman bioética) son una orientación, no la orientación para actuar.

La generalidad u universalidad de un enunciado bioético debe considerarse desde una perspectiva epistemológica (cuál sea esta epistemología, es otro tema). Cuando se habla de principios bioéticos (principios de la bioética, como suele rezar en los manuales), cabe cuestionar la validez ética y epistémica de esos principios.

Cabe pensar, sin embargo, si puede hablarse con propiedad de un principio bioético legítimamente, y si cabe hablar de un principio verdadero. Apelar a la verdad de un principio, en ética o bioética, es consentir implícitamente la existencia de cierto naturalismo ético. Más que de verdad de un principio, puede hablarse de razonabilidad de un principio. Sin caer en positivismos éticos radicales, hay que aceptar que la noción de verdad ética es el producto de cierto consenso racional de cierta cultura o sociedad. La ética no escapa a la construcción de la racionalidad, y la racionalidad es un constructo social.

Los principios que orientan el quehacer bioético no logran determinar a cabalidad lo que tiene que entenderse por autonomía o beneficencia sin caer en contradicciones lógicas y éticas. La noción de autonomía no tiene lugar en una ética cristiana, por más que se habla de libre albedrío. O bien, la noción de autonomía desaparece ante el interés social, según una perspectiva milleana. Y no se diga de la ambigüedad de la autonomía kantiana, dejando en ella el grado más puro de racionalidad. Pero más allá de estos constructos teóricos, deleite de las cátedras universitarias, las comunidades construyen su propia racionalidad; los individuos construyen su propia racionalidad. Los espacios socioculturales construyen una racionalidad focalizada 
de acuerdo con sus intereses. Cierto grupo de investigadores, movidos más por el control del mercado que por el bienestar humano, pueden interpretar, a su antojo, los principios de autonomía y beneficencia. De ahí que tomar cuatro principios y aplicarlos a un protocolo de investigación científica, no tiene ningún mérito ético ni intelectual.

Entonces, más allá de delimitaciones filosóficas, debe considerarse la vida real, la vida cotidiana, donde conceptos como beneficencia y autonomía están sujetos a marcos axiológicos, o bien, a racionalidades. Así, la noción de autonomía puede verse imposibilitada por asuntos como la cultura, el lenguaje, la educación, los recursos económicos, entre otros. Es fácil hablar de autonomía, pero difícilmente una persona, con plenas facultades racionales y físicas, logre una plenitud autónoma. Por su parte, la práctica de cierta racionalidad determina lo que un individuo entienda por beneficencia. Por ejemplo, discutir el tema del aborto por violación, no es lo mismo para un diputado con valores religiosos que para otro sin esos mismos valores. De igual forma, a la hora de intervenir ante una situación de aborto por violación, el principio de actuar en beneficio de la persona es diferente para un médico católico (por especificar una práctica religiosa) que para un médico agnóstico, ateo, laico o radicalmente materialista, entre otros.

Los principios que pretenden orientar el quehacer bioético no orientan unívocamente sino en el contexto o situación particular en la que vive el sujeto. Se hablaría entonces de una casuística dentro del principialismo. Este tema lo discute Diego Gracia, en el apartado Cuestión de principios, de su obra fundamentación y enseñanza de la bioética (2000).

No se duda de la utilidad práctica de los cuatro principios, pero no se puede decir, sin más, que son los principios de la bioética, sino que son una reflexión racional más sobre la experiencia moral.

El sentido común moral perfectamente puede ser un recurso para orientar la vida personal cotidiana, pero no para orientar la toma de decisiones éticas o bioéticas. Por tanto, es perentorio someter a una mayor discusión racional el contenido de estos enunciados éticos. Si no existe claridad en el contenido, ¿cómo pueden los principios orientar acertadamente la vida práctica?

Tampoco se trata de hacer radicalizaciones ingenuas, y creer que no existe racionalidad en el quehacer bioético. Considerar que es tarea de una bioética racional y secular ciertos modos argumentativos para desacreditar 
los postulados absolutos, y abrirse a la pluralidad y la tolerancia, no deja de ser dramático. Somos personas razonables, pero tomar la racionalidad ética como forma de abordar los enunciados éticos puede orientarnos a ser más razonables, toda vez que se parte de la idea de que cualquier principio o enunciado ético debe someterse a crítica colectiva y personal. En esto, la ética discursiva tiene mucho que enseñarnos.

Un concepto recurrente en bioética es el tema de la autonomía. Teóricos como Beauchamp y Childress consideran esencial para la autonomía personal, la propia regulación personal, libre, sin interferencias ni limitaciones que pretendan controlar al individuo. Se habla entonces de respeto a la autonomía, cuya condición fundamental consiste en asumir el derecho que tiene un sujeto de tener opiniones propias, elegir y realizar acciones basadas en sus valores y creencias personales (1999, p. 113-117).

De la misma forma que existen grados de responsabilidad, también existen grados de libertad. La libertad humana, física, moral o psicológica no puede reducirse a una autonomía común. Tener libertad para actuar implica tener concepciones claras de lo que es correcto e incorrecto, justo e injusto, bueno o malo. Por ejemplo, un acto de justicia es filosóficamente problemático, como lo testimonia la historia de las ideas. A nivel individual, una persona puede atribuirse el grado de justo, por creer que está actuando de forma benevolente. Sin embargo, no es positivamente el principio de beneficencia lo que indica la acción, sino el marco axiológico particular del individuo lo que determina la interpretación de lo que es esa benevolencia. El principio, de esta forma, queda a merced de una interpretación moral.

En el contexto de la CCSS (Comités de Bioética, 2006), el principio de autonomía se entiende como "el respeto a la libertad de las personas de decidir con respecto a la aplicación de un método diagnóstico o un tratamiento, por parte del personal de salud, o bien, con respecto a su participación en una investigación." Esto es un enunciado cosméticamente loable. Sin embargo, la libertad de un paciente es muy limitada. Si ya partimos de una libertad condicionada en nuestra vida cotidiana sin mayores impedimentos, una persona en estado de vulnerabilidad, física y psicológica, no puede ser llamada libre, y dejar en ella la responsabilidad para eximirse de culpa. La autonomía, en los contextos hospitalarios, es un principio que carece de 
legitimidad ética. Y aquí empieza el principialismo como base de la bioética a presentar problemas éticos fundamentales.

La autonomía no es un principio válido para cualquier lugar y circunstancia, con lo que la apertura de una pluralidad ética es lo más favorable. Como señaló Casanova (2008) líneas más arriba, la libertad no puede reducirse a una autonomía común a todos los seres vivos, ni existe, agrego de mi parte, una autonomía tal que puede garantizar una libertad completa, ni una completa libertad que pueda ofrecer una auténtica autonomía. Tratándose de pacientes, la autonomía se reduce por su estado de vulnerabilidad. Y allí donde existe vulnerabilidad no se puede hablar de autonomía ni de libertad de elección.

No puede aplicarse el principio de autonomía por igual a todas las personas, porque no todas las personas gozan de autonomía. Por otra parte, el tema de la libertad está ausente cuando se habla de autonomía. Un comité de bioética puede incurrir en error si sigue fielmente los principios clásicos de la práctica biomédica, pues dejaría por fuera todo análisis en relación con la libertad de los pacientes. En cuanto a investigaciones y la revisión de protocolos, la autonomía queda sujeta a un enunciado, dejando a criterio de una lectura si se cumple o no tal principio.

No se puede llamar autónomo a un paciente con baja escolaridad, ni tampoco a un paciente en estado vulnerable de indefensión. El principio de autonomía encuentra implicaciones serias a la hora de aplicar su pretendido universalismo en ciertos contextos. Por ejemplo, cuando un paciente se encuentra en total estado de indefensión, ¿cómo puede aplicarse el enunciado: libertad de las personas de decidir con respecto a la aplicación de un método diagnóstico o un tratamiento, por parte del personal de salud, cuando ni siquiera es capaz de manifestar coherentemente sus deseos más elementales? ¿Autonomía de qué? El enunciado de que un sujeto tiene el derecho de tener opiniones propias, elegir y realizar acciones basadas en sus valores y creencias personales parece aplicarse en el reino de los fines, el mundo racional, no en un mundo de indefensión, de precariedad emocional y física, en una palabra, de vulnerabilidad.

Ante una situación como la anterior, sólo resta apelar al famoso principio de beneficencia. Sin embargo, la beneficencia, no es tampoco un concepto que garantice una aplicabilidad sin cuestionamiento ético alguno. 
En el contexto de la CCSS se entiende por beneficencia "hacer el bien". La beneficencia "obliga al personal de salud a realizar un análisis de los beneficios y riesgos antes de tomar una decisión relacionada con la salud del usuario." (Comités de Bioética, 2006) Hacer el bien es problemático.

La labor de la reflexión filosófica y el ejercicio de la racionalidad ética en particular, empiezan por cuestionar los fundamentos que sostienen la idea de correcto. Esto en cuanto correcto es equiparado con bueno, y bueno, para muchos, remite a los principios religiosos, esto es, a los mandamientos contenidos en la Biblia. Nótese que el principio demanda hacer el bien, el hacer el bien queda sujeto a una interpretación de acuerdo con el marco axiológico de cada persona. No se puede hablar objetivamente de un bien en el contexto del enunciado.

Así las cosas, la beneficencia es la labor del buen samaritano, una labor de Dios. Pero esa buena intencionalidad moral, desde un punto de vista religioso, en lugar de beneficiar, podría perjudicar al paciente no autónomo. Póngase por caso otro escenario hipotético más: una mujer embarazada en estado de demencia. Una discusión ética básica tiene que ver con el principio de interlocución. Este principio ético nos orienta a asumir responsabilidad de las acciones cuando existe acuerdo producto del diálogo, de la deliberación emotivo-racional, en una palabra, cuando existe interlocución. En este sentido, un embarazo es el deseo de dos personas que deciden, emocional o racionalmente, embarazarse. No puede existir un embarazo cuando existe imposición o violencia sobre una persona que contraviene su propia voluntad. ¿Qué pasa cuando una mujer en estado de demencia es violada y como producto de esa violación surge el embarazo? ¿Cómo aplicar los incuestionables principios de autonomía, beneficencia, no maleficencia y justicia? Si se le practica el aborto, ¿dónde queda la autonomía? Pero igualmente, si se e practica el aborto pensando en su beneficio, ¿desde qué punto de vista puede considerarse beneficio? Lo mismo se dice cuando no se interviene y se deja que el curso de la suerte (injusticia objetivamente planeada) siga su rumbo porque es la voluntad de Dios... Cabe toda posibilidad de que existen profesionales en salud que consideran incorrecto provocar el aborto a una mujer (en estado de demencia o en cualquier estado) porque se irrespetaba el principio de vida. Pero no el principio de vida desde un punto de vista biológico, sino espiritual o divino. No se puede alterar la voluntad de Dios. 
Cuando asuntos divinos se mezclan con asuntos éticos se pierde la objetividad racional.

Aquí estamos en presencia de un conflicto ético entre principios. En este caso, el principio de autonomía y el principio de beneficencia. Sin embargo, estamos en presencia de una interpretación de principios. De ahí que algunos le apuesten a la hermenéutica en bioética como criterio de objetividad a la hora de realizar análisis ético.

Es evidente que, en casos como este, dependiendo del marco axiológico (conjunto de valores), así serán las acciones humanas. El principio de beneficencia, que busca procurar el bien, queda, en última instancia, a merced del conjunto de valores que tenga el profesional en cuestión. Es decir, que la interpretación de hacer el bien, depende significativamente de qué entiende la persona por bien. Hay razones para cuestionar unos principios que orientan la toma decisiones. La autonomía y la beneficencia dependen del marco axiológico de cada uno.

Desde luego que, en el caso del principio de beneficencia que establece la CCSS (Comités de Bioética, 2006), hay más objetividad en la parte en la que se afirma que la beneficencia "obliga al personal de salud a realizar un análisis de los beneficios y riesgos antes de tomar una decisión relacionada con la salud del usuario". Esto, sin duda, está más próximo al ejercicio razonable de la reflexión ética, o bien, racionalidad ética, en tanto que existe una apertura para el análisis de los riesgos y beneficios que un curso de acción puedan tener sobre la calidad de vida de un paciente. Esta apertura de análisis ético es lo que busca la bioética como práctica profesional.

Según Beauchamp y Childress, la beneficencia es la virtud y la obligación moral de actuar en beneficio de otros, es decir la acción beneficente es aquella acción moral que pretenda beneficiar a otras personas (1999, p. 246). Beneficiar a otros es, como se indicó, problemático. Analizar riesgos y beneficios como punto de partida a la hora de intentar beneficiar a alguien es mucho más razonable y éticamente aceptable.

Al ser una acción moral, esta puede contener presupuestos ajenos a una racionalidad ética. El marco axiológico opera como marco interpretativo del principio de beneficencia, quedando a criterio del sujeto moral qué cosa es la beneficencia. La práctica del bien está condicionada por los valores morales particulares. Si los principios de la ética biomédica se mezclan 
con moralidades religiosas, el problema es mayor, en tanto se parte de una interpretación distorsionada de lo que sería autonomía y beneficencia. Tómese en cuenta que para esa comunidad ambos puntos son, en última instancia, voluntad de Dios. ¿O acaso en nombre de una moral católica se puede justificar el aborto, la eutanasia, la eugenesia, la fecundación in vitro, el matrimonio homosexual? Parece que el marco axiológico determina la interpretación del principio de beneficencia.

No existe problema alguno si todo marco axiológico fuera discutible, cuando discutirlo redunda en beneficio o perjuicio de otras personas, o bien, de otras formas de vida. Cada quien en su vida personal puede arreglar su vida conforme a un conjunto de valores particulares, pero en el momento en que esos valores pretenden, de alguna forma, interferir en la vida de otros, hay que someter a análisis las bases de ese marco axiológico.

La moral vivida consiste en la incorporación de una serie de normas a las cuales se les ha otorgado un estatuto de validez social. El ejercicio de una racionalidad ética consiste en analizar el estatuto de validez de esas normas morales. Si bien es cierto el principialismo es una fundamentación teórica orientada a la vida práctica, y en este sentido es una ética legítimamente planteada, no por ello podemos dejar de cuestionar sus alcances prácticos. Esta es, y será, la labor específica de la ética: reflexionar y analizar la validez de los enunciados éticos en cuanto a sus implicaciones y alcances prácticos. El ejercicio de la racionalidad ética procura realizar esta tarea de manera más atenta.

\section{Marcos axiológicos y marcos epistémicos: el problema de la objetividad.}

Un marco axiológico es el conjunto de valores morales que una persona asume como intrínsecamente buenos o correctos. Las normas constituyen un fuerte marco axiológico que sirven no solamente para fundamentar los juicios, sino para orientar la vida práctica.

Dos enfoques psicológicos que podrían ofrecer cierto respaldo teórico a la noción de marco axiológico los encontramos en las teorías del desarrollo moral de la transmisión y las teorías cognitivas. Estas teorías nos sirven para explicar la noción de marco axiológico. La forma como un individuo 
aprende su campo de acción moral tiene que ver con el aprendizaje de estos marcos axiológicos.

De acuerdo con las teorías de la transmisión, "los valores, actitudes y conductas sociales que etiquetamos generalmente como morales, han sido adquiridas por el sujeto mediante aprendizaje, a través de los mismos mecanismo que gobiernan la adquisición y el mantenimiento de las demás conductas, esto es, a través de refuerzos, castigos y aprendizaje por observación.” (Carranza y Escudero, 1999, p. 45). Por su parte, las teorías cognitivas del desarrollo moral sostienen que "los avances en la capacidad del razonamiento moral dependen del incremento de las capacidades cognitivas generales que tienen lugar a lo largo del desarrollo." (Carranza y Escudero, 1999, p. 49). Esta teoría tiene su punto de apoyo evidentemente en la tesis doctoral de L. Kohlberg, en el año 1958.

Tomando como punto de referencia ambos enfoques teóricos, se desprende, sin mayor esfuerzo, que el desarrollo moral es en realidad un proceso de toda la vida. Esto porque contamos con influencias morales adquiridas por imitación y reforzamiento a lo largo de un periodo de absorción moral, a la vez que reflexionamos sobre el contenido de nuestros juicios morales. El razonamiento moral no es una labor puramente cognitiva. La cognición es la base que permite construir el edificio de nuestra moralidad. Pero en ese edificio existe una serie de costumbres culturales que no va a desaparecer tan fácilmente. Somos pues el resultado de un conjunto de razonamientos morales que provienen de la experiencia y conceptualización teórica de lo que es y no es correcto hacer.

El problema fundamental que presenta el principialismo es el criterio de rigurosidad conceptual. Cada principio se interpreta a la luz de un marco axiológico particular. Incluso, este marco axiológico va más allá de lo puramente moral. El marco axiológico tiene alcances ideológicos, políticos, filosóficos, entre otros.

Esto quiere decir que conceptos como autonomía, justicia y beneficencia se interpretan de acuerdo con el marco conceptual o marco de referencia teórico que cada profesional interprete como política y moralmente correcto. Se podría pensar que bajo tales circunstancias caeríamos en una suerte de relativismo epistémico y que el sujeto no tiene la capacidad de discernir objetivamente entre la validez epistémica de una teoría y otro. La historia nos 
muestra, y la vida cotidiana aún más, que muchos profesionales se aferran a concepciones teóricas de forma casi religiosa. Existen intelectuales que leen la realidad a partir de un autor, de una obra, de una doctrina.

Es necesario un análisis riguroso sobre los fundamentos que respaldan el marco axiológico que estamos sustentando. Porque, si vamos a emitir criterios de lo que es correcto y de lo que no es correcto, antes hay que examinar las bases que legitiman como correctos los enunciados éticos desde los cuales vamos a juzgar las acciones humanas. Por esta razón es de vital importancia analizar el discurso ético que sustentamos. Cuando afirmamos: "es éticamente incorrecto", el juicio supone estar en propiedad de dos condiciones fundamentales: 1) que estamos en posición de hacer juicios éticos sobre los actos humanos de la forma correcta; 2) que practicamos una ética o una moral correctas, que permiten juzgar sin equívocos la rectitud o no rectitud de los actos humanos.

Realizar estos cuestionamientos filosóficos es la invitación al ejercicio de la racionalidad ética. Aceptar principios éticos, porque provienen de figuras de autoridad históricas, no solamente es ingenuidad intelectual dogmática, sino irresponsabilidad intelectual. La negligencia con la que asumimos posiciones morales y orientaciones éticas se hará sentir en el ambiente social, cualquiera sea esa ambiente: humano, animal, ambiental.

Por su parte, si el marco epistémico desde el cual estamos elaborando pensamiento bioético no es consistente, los principios, a los cuales les otorgamos objetividad moral, no serán consistentes.

Un marco epistémico es un conocimiento racionalmente bien sustentado que proporciona criterios de objetividad para valorar las creencias y opiniones con las que nos referimos a la realidad. Un marco epistémico presenta las bases firmes que tiene una persona para considerar verdadero la creencia o conjunto de creencias asumidas. Es decir, un marco epistémico valida las opiniones que una persona manifiesta sobre cualquier tema.

Todos consideramos tener pensamiento crítico en la esfera académica. No es fácil aceptar que partimos de ciertos dogmas en la elaboración de nuestras ideas. Las creencias están legitimadas en nuestras estructuras cognitivas como racionalmente consistentes, por lo que nos resulta imposible aceptar que tomamos algunas dosis dogmatismo. 
Es necesario pensar la epistemología porque es necesario pensar las bases desde las cuales legitimamos el conocimiento humano, nuestro propio conocimiento. Si la tarea consiste en encontrar el puesto de la epistemología en bioética, antes hay que examinar la perspectiva epistemológica desde la cual vamos a referimos o evaluar a la bioética. Esto quiere decir que si el marco epistémico de la bioética lo constituye un conjunto de normas jurídicas, la epistemología bioética será esencialmente jurídica. De igual forma si asumimos una epistemología católica, una epistemología ecológica, una epistemología clínica, una epistemología filosófica, etc. Por ejemplo, en el contexto filosófico se puede asumir tesis epistemológicas provenientes de varios marcos de referencia teóricos, específicamente autores: Bachelard, Popper, Feyerabend, Gracia, Ottois, e incluso, habrá quien resucite a Platón desde la profundidad de la caverna para fundar una epistemología crítica de la bioética. Lo cierto es que cualquiera sea esa epistemología, el marco epistémico debe ser consistente. Después de todo, la epistemología tiene que ver con un conjunto de categorías que orientan la forma como elaboramos y producimos conocimiento, para comprender y actuar sobre la realidad que nos envuelve.

La noción de análisis de perspectiva es importante para abordar lo que en epistemología suele llamarse sustentación de una creencia. Es decir, todos, sin excepción, partimos de cierta perspectiva para interpretar el mundo simbólico que nos rodea. Y esto tanto en la vida académica como en la vida práctica de a pie. Asumimos una perspectiva antropológica para dar cuenta académicamente lo que es el ser humano, e igualmente asumimos una perspectiva antropológica para enfrentarnos con ese ser humano de la calle, ese extraño que nos pide unas monedillas para alimentarse o para drogarse. Ante él asumimos una perspectiva psicológica y antropológica callejera que nos condiciona a tener un criterio sobre la verdad o falsedad de esa historia narrada, que nos condiciona a temerle quizás, a rechazarlo; pero en la cátedra universitaria elaboramos discursos bienaventurados sobre derechos humanos y teoría de la justicia...

Es imposible no asumir una perspectiva para valorar el mundo. Por esa razón es importante asumir un análisis de perspectiva para dar cuenta de cuánta validez y objetividad podemos alcanzar con ella. 
El análisis de perspectivas se considera una destreza intelectual susceptible de ser enseñada, la cual consiste en tomar conciencia de las opiniones y creencias que tenemos sobre la información que damos o recibimos contrastándola con las opiniones o creencias que pueden tener otras personas (Beas, et al., 2008).

No es posible tomar una perspectiva en el vacío. Cada vez que asumimos una perspectiva teórica, de alguna forma contamos con algún conocimiento previo que nos hace valorar epistémicamente la calidad de esa perspectiva. El problema se da cuando la justificación de la creencia que antecede la elección no cuenta con una buena sustentación. En este caso la adopción de una perspectiva de análisis puede ser tomada a la ligera. Creemos en algo porque nos da seguridad racional o emocional.

Aprender a analizar las perspectivas que potencialmente vamos a asumir nos obliga a revisar la información contenida en la perspectiva y desde la cual haremos afirmaciones. Se trata del molde teórico-cognitivo desde el cual predicamos sobre la realidad. La perspectiva que asumimos para producir conocimiento es muy importante. Desde ella elaboraremos juicios a los que atribuimos validez epistémica y moral, entre otros.

En una perspectiva de conocimiento subyacen valores de todo tipo y aparejado a estos valores, intencionalidades. La tal muerte del escritor es un mito. El autor tiene intencionalidad en la escritura, y quiere que la realidad se conforme de acuerdo con sus ideas. La responsabilidad a la hora de asumir una perspectiva es más importante de lo que podríamos imaginar. Podríamos estar hablando desde el vacío intelectual, estructurando nuestros argumentos lábilmente y aceptando pasivamente argumentaciones sin mayor sustentación.

Si bien es cierto que existe formas diversas para cultivar una actitud crítica ante las perspectivas que asumimos (las creencias, sin más) se debe comenzar por la toma de conciencia de las razones que subyacen a las propias creencias (Beas et al, 2008). Es decir, analizar las creencias propias nos coloca de plano en lo que consideramos realmente valioso o a lo que le damos mayor validez moral y epistémica. En cuanto a las perspectivas que asumimos o queremos asumir, se debe examinar la información contenida en ella, tratando de identificar el propósito central del texto en cuestión. Se tiene que revisar las opiniones, procurando evidenciar los juicios de valor subyacentes. No es lo mismo describir un hecho que realizar juicios de valor 
sobre un hecho. Cuando asumimos una perspectiva, asumimos un conjunto de argumentaciones implícitas: creencias morales, principios éticos, marco ideológico, filiación política, etc. La tarea siguiente es preguntarnos por qué hemos asumido como verdaderas o moralmente aceptables los juicios establecidos en las opiniones.

Atribuirle valor a una perspectiva implica concederle una gran cantidad de atributos epistémicos. Se le concede legitimidad a la información, al propósito, a los juicios de valor y a los argumentos ofrecidos, los cuales adquieren relevancia desde puntos de vista diversos: científicos, filosóficos, religiosos, políticos, etc. De esta forma, dogmas como el principialismo en bioética merecen ser revisados para determinar cuál es el marco epistémico que los sustenta. ¿Autonomía? ¿Autonomía desde que enfoque? ¿Beneficencia? ¿La beneficencia basada en cuál marco axiológico? No se comprende de forma unívoca el principio de beneficencia ante un caso de aborto o eutanasia, si el marco axiológico del agente moral es católico o liberal, como se ha visto líneas arriba.

Cuando atribuimos valor a personas o cosas, la información que recibimos sobre ellos se ve de alguna forma alterada. El valor atribuido, o la opinión, sobre una persona o sobre una cosa, produce cierto sesgo a la hora de recibir nueva información, al punto de condicionar la objetividad de nuestros juicios. Algunos consideran que la atribución de valor es una fuerza tan poderosa que es capaz de hacer descarrillar la objetividad de nuestros juicios (Brofman y Brofman, 2009). De alguna forma, cuando atribuimos valor a una perspectiva, no nos percatamos del dogmatismo en el que caemos. Piénsese por ejemplo en ese fervor estudiantil de izquierda o de derecha. La perspectiva es asumida de forma tan apasionada que la cadena de razonamientos que lanza un joven en relación con la realidad política actual precipita hacia ese descarrilamiento de objetividad de los juicios. Pues lo mismo sucede en bioética cuando se habla categóricamente de los cuatro principios de la bioética, de suerte que no fueron diez principios, porque estaríamos ante las nuevas tablas de Moisés...

La actitud crítica demanda de mucha rigurosidad conceptual, el cual supone un ordenamiento epistemológico y metodológico que permite legitimar conocimientos a nivel social con miras a una universalidad. Sobre este punto cabe cuestionar en qué situación se encuentra la bioética principialista 
a la hora de pretender legitimar sus aportaciones como herramientas de conocimiento humano.

Todo conocimiento que sea auto-referencial cae en un dogmatismo ingenuo. En bioética nos hace falta pensar y recrear críticamente las prácticas del conocimiento que estamos realizando. En la bioética hospitalaria se procede desde un marco operativo orientado por datos clínicos sin que haya un instrumento de análisis epistemológico que legitime los juicios éticos emitidos. No estamos pensando críticamente la bioética, si por crítica entendemos la forma de pensamiento fundamentado en un sólido marco epistemológico que indique porqué unos juicios éticos deben ser el fundamento de un análisis que pretende regular toda actividad investigativa humana, y por qué otros juicios son descartables.

Jonathan Dancy (1993, p. 15) sostiene que la epistemología es el estudio del conocimiento y de la justificación de la creencia, donde el cuestionamiento sobre los fundamentos que legitiman tanto el saber como la creencia, constituye el corazón de la epistemología, aceptando que las fronteras de la epistemología son más bien difusas. Nótese en Dancy que presenta la epistemología como el estudio del conocimiento y de la justificación de la creencia. Sin embargo, de creencias está atestada la vida humana, y más que justificar o estudiar creencias, en aras de un conocimiento en el que se pueda confiar con algún grado de certeza, interesa, filosóficamente, la validez o justificación del porqué la validez de un determinado conocimiento. Un buen análisis epistemológico tiene que enfocarse no ya en justificar una creencia, sino en porqué la creencia tiene validez qué argumentos sustentan esa validez.

Ciertamente en bioética hemos creado un paradigma a todas luces falso. Se trata del paradójico paradigma de la disciplina que puede establecer juicios de lo correcto e incorrecto de las prácticas científicas y tecnológicas. Para que este paradigma pueda tener validez, antes debemos, en bioética, sentar las bases epistemológicas que legitimarán la elaboración de juicios éticos, o bien, de juicios bioéticos. Es decir, tenemos que empezar por hacer una revisión epistemológica (un estudio del conocimiento y de la justificación de la creencia) del cuerpo categorial desde el cual estamos interpretando y actuando sobre la realidad social. No vaya a ser que la bioética se convierta en un discurso políticamente correcto. 
En este orden, el procedimiento metodológico para darle estatuto de disciplina a la bioética, reside en mostrar cuáles son las bases epistémicas por las cuales pretende referirse a aspectos normativos de otras disciplinas bajo el criterio de juez de la rectitud moral. Estas bases epistémicas o bases epistemológicas deben presentar un marco de referencia metódico, es decir, la bioética tiene que presentar cuál sería su marco metodológico de acción mediante el cual pretende universalizar sus juicios normativos. Este marco metodológico supone la adquisición de un marco categorial, esto es, el conjunto de categorías propias de esta disciplina que puedan ser empleadas en cualquier parte del hemisferio terrestre sin temor a caer en relativismo culturales. Las bases epistémicas de la bioética permitirían una mayor legitimidad de sus juicios normativos éticos. Punto, por cierto, controversial, dado que la bioética no cuenta con una ética claramente definida, pese al intento de muchos de ver en el principialismo el fundamento por excelencia de la bioética.

Así pues, no se puede perder de vista la pregunta: ¿Puede una disciplina como la bioética orientar las prácticas científico-tecnológicas aun careciendo de un sólido fundamento epistemológico?

\section{El principialismo o el dogma de la bioética}

Solo haciendo votos de ingenuidad podríamos considerar que ya contamos con un método en bioética. Y más aún, solo cayendo en cierto dogmatismo ingenuo consideraríamos que la bioética cuenta con un marco ético claramente definido.

Cuando consideramos que el principialismo representa la ética de la bioética supone contar con unos fundamentos muy lábiles. El principialismo es una ética enfocada al ejercicio clínico, propiamente médico. Es una ética médica en el campo de la investigación.

Para abordar este problema, a saber, el principialismo como dogma en bioética, es necesario aclarar qué es un reduccionismo y cuáles son sus implicaciones epistemológicas.

Un enfoque reduccionista conlleva una distorsión en el proceso epistémico de comprender la realidad en sentido global porque particulariza y hasta eleva a dogma esa particularización de aproximarse a la realidad. En sentido 
clásico, se comprende por reduccionismo la equiparación de lo real con lo verdadero, donde el átomo es la partícula fundamental que le da sentido a esta realidad (Pérez, 1998). Pero de igual forma se habla de otras formas de comprender el concepto reduccionismo. Algunos consideran (Bunge, 2005) que es mejor hablar de un reduccionismo moderado, cuya tesis elemental consiste en afirmar que se puede reducir tanto como se pueda sin ignorar formación y descomposición de los sistemas, la aparición o desaparición de nuevas propiedades emergentes o sumergidas. En otras palabras, reducir aceptando la complejidad en la dinámica física y social, y los movimientos que generan cambios.

Si tuviéramos que apostar a un concepto de reduccionismo en el campo de la bioética, se puede considera el hecho de equiparar el principialismo biomédico con bioética. En este sentido, el reduccionismo bioético consiste en creer que el principialismo es el único marco de referencia ético y epistemológico de la bioética ignorando por completo otras bases filosóficas que le dan legitimidad.

Pasamos de un reduccionismo, epistemológica y éticamente insostenible, para caer en brazos de un dogmatismo ingenuo. El dogmatismo consiste precisamente en considerar como marco epistémico y marco axiológico los cuatro principios biomédicos, derivados del Informe Belmont y de los Principios de ética biomédica. De esta forma fragmentamos (reducimos) la complejidad de los problemas humanos bajo una única perspectiva bioética. La bioética se dogmatiza en el momento que la consideramos acabada. Se vuelve ingenua desde el momento que confundimos simplificar con simplicidad.

Desde luego que estamos en presencia de un dogma ingenuo cuando tomamos como punto de referencia cuatro principios a la ligera y desde ellos revisamos protocolos para determinar si se cumple con el principio de autonomía o no, si se cumple con el principio de beneficencia o no, si se es justo no maleficente.

\section{Más allá del principialismo: hacia una reconceptualización de la bioética}

Conceptualizar es, básicamente, el proceso enfocado a desarrollar conceptos sobre algún tópico en particular. Reconceptualizar, entonces, es volver a conceptualizar. Ante la imprecisión de un concepto, la reconceptualización 
busca ofrecer argumentos para proporcionar un nuevo enfoque conceptual. Esto se puede dar por muchas razones, entre ellas, porque el concepto no satisface en su significación, porque el concepto no logra corresponderse con la realidad que predica, porque existe necesidad de agregar algo al concepto; o bien, para proponer un punto de vista diferente sobre una tema determinado.

Ir más allá de la bioética tradicional supone abordar los mismos temas recurrentes desde otra perspectiva de análisis. Algunas consideran que la hermenéutica filosófica ofrece las herramientas para convertir la bioética en un marco de referencia epistémico para el análisis de situaciones diversas.

Asuntos tradicionales como derechos humanos, investigación científica, la protección de la vida; temas recurrentes como la eugenesia, la eutanasia, la investigación con embriones; o nuevos temas emergentes, como el feminismo, el medio ambiente, el derecho de los animales, y el civismo bioético, van más allá de cuatro principios que pretenden ingenuamente universalidad.

Ir más allá del principialismo implica abandonar la ingenuidad dogmática de considerar que la bioética se compone de cuatro principios. Ningún problema humano, de hombres, mujeres, niños y niñas, de animales, de genes y neuronas, del medio ambiente y de la sociedad en general, puede abordarse desde cuatro principios generales. La bioética va más allá de este reduccionismo conceptual.

Los nuevos retos que nos lanzan la nanotecnología, la neurociencia, la biotecnología, así como los retos emergentes en el terreno geopolítico van más allá de un bioética y una ética clásica. Las éticas clásicas sirven para orientar el análisis, pero no pueden responder concretamente a la multiplicidad de problemas humanos. El dinamismo racional debe permitir un acercamiento diferente al concepto tradicional de ética y de bioética. Para tal fin se debe reconceptualizar la bioética.

Si hablamos de reconceptualizar el concepto de bioética, primero se debe contar con alguna idea lo que es. Y con esta tarea empieza el rompecabezas para los foráneos de la bioética. La bioética, igual que la ética, así como la filosofía en general, ofrece muchas definiciones. Al no ser concretamente una ciencia, tampoco una disciplina definida, las definiciones varían de autor a autor. Para Pardo (2010, p. 20), se entiende por bioética "la parte de la ética que se dedica a estudiar las acciones técnicas del hombre en el 
contexto de la biomedicina (...)”. Enfatiza, además, que este contexto se entiende en dos ámbitos: profesiones sanitarias y biología.

Si la bioética es el resultado de un análisis ético, ¿para qué bioética? La reconceptualización de la bioética no solo apunta hacia la bioética en sí, sino hacia los que producen manuales en el campo de la bioética, a los teóricos de la bioética. Además, nótese el reduccionismo profesional en el concepto que tiene el autor de bioética: únicamente profesiones sanitarias y biológicas. Deja por fuera sinnúmero de asuntos humanos abordables desde la bioética. ¿Qué es bioética entonces y cómo conceptualizarla y reconceptualizarla? Un primer inicio es situarla en su contexto real: sus alcances y limitaciones.

Hoy día enfrentamos problemas producto del quehacer científico y tecnológico de forma más vertiginosa. La tecnociencia se yergue como una industria que cuantifica el poder. La ciencia se capitaliza, es un producto que genera ingresos económicos sustentables. Cuando el interés enfáticamente económico es la lógica que mueva la racionalidad el problema encuentra un punto de ebullición mayor.

Dentro de la capitalización de la ciencia, y en sentido estricto, dentro de la capitalización de la vida, la bioética debe ofrecer respuestas, no interrogantes. La bioética no puede adoptar ese idealismo ingenuo de la filosofía de conformarse con plantear problemas más que respuestas. Una bioética que siga ese norte puede fracasar. La bioética debe ofrecer respuestas a problemas sociales. De hecho la filosofía también, pero la costumbre es tal, que la tradición se ha tomado como dogma. Aceptemos que la filosofía contempla ideas, pero tiene que bajar a la calle a ponerlas en práctica.

Dentro de la reconceptualización de la bioética, un nuevo interlocutor aparece como un agente moral más que reclama un espacio merecido dentro del análisis, práctica y alcance de la bioética: la condición femenina. Según Feito (2010), en bioética la voz de la mujer es marginal. La generalización de los principios impide una ética más situacional, y por esta razón, nociones como el de autonomía pierde sentido. De ahí la importancia de una "autonomía relacional”, según la expresión de Lydia Feito. Este es otro punto en el cual la bioética debe reconceptualizarse. Algunos agentes morales quedan por fuera del discurso reduccionista de la bioética clínica. La bioética va más allá del protocolo clínico para investigación, la bioética debe situarse 
en un contexto más amplio procurando responder a la problemática moral y política que enfrenta el ser humano en su día a día.

Si la ética ha querido ser normativa, ¿la bioética debe orientarse por el mismo sendero? Navarro señala que "la tarea de la bioética no es descriptiva, sino eminentemente crítica y normativa" (2009, p. 357). Para considerar la bioética crítica, antes debe realizar una introspección de sus fundamentos epistémicos. ¿Desde qué marco epistémico ejerce pensamiento crítico la bioética? ¿Desde el principialismo? Si fuera así, la bioética sería acrítica.

De acuerdo con Navarro (2009, p. 359), hace falta una "hermenéutica bioética". Generalmente "se asocia al problema de la ética la pregunta en torno a si algo es bueno o malo, correcto o adecuado, pero no es tan frecuente plantear que uno de los objetivos del razonamiento moral sea dilucidar y justificar qué significa la salud". En este sentido, no solamente qué es salud, sino calidad de vida. Pensar en calidad de vida implica pensar necesariamente en calidad de muerte. Con lo que una hermenéutica bioética nos obliga a pensar un conjunto de conceptos relacionados: vida, salud, enfermedad, muerte. El giro hermenéutico apunta a dilucidar qué cosa es la salud, la muerte, la vida, la enfermedad. Sin embargo no es así.

Buscamos en todo momento darle sentido a las cosas. Tanto la llamada hermenéutica como la filosofía buscan dotar de sentido, de significado el texto que los rodea. Por tanto, tratar de interpretar los textos (texto es todo lo que nos rodea, incluyendo nuestros pensamientos) es parte del quehacer filosófico, enteramente humano. "La interpretación como objeto de la hermenéutica es una búsqueda incesante de sentido”. (De Alba, 2014, p. 96). En esta búsqueda, el asunto cultural, más concretamente, el contexto cultural, es vital porque determina cómo se interpreta y a la luz de qué se interpreta. No es lo mismo comprender el concepto de autonomía en un contexto que ha privilegiado la libertad (moral, económica, religiosa) que en un contexto que ha suprimido, negado, o subyugado estos mismos principios.

Pero la construcción de esta perspectiva interpretativa no parece estar clara en el campo de la bioética. La interpretación bioética de problemas humanos en el campo de las ciencias biomédicas o de la investigación científica está sujeta a un marco axiológico que determina la hermenéutica misma, o bien, que se convierte en la misma hermenéutica. En este sentido, el problema de una hermenéutica de la bioética es que queda en 
un enunciado. Así lo deja ver Villarroel (2000, p. 151) cuando escribe que resulta factible concebir la bioética en relación con una perspectiva de naturaleza hermenéutica (...). Aquí el problema fundamental es no saber cuál es esa perspectiva.

La bioética tiene que ver con un giro en su marco epistémico. Este sería el giro hermenéutico. Para que este giro se dé, se debe reeducar en bioética principalmente a los fans de la bioética como palabra, como neologismo inocente, y mostrarles las implicaciones que conllevan sostener un marco axiológico que apele a la religión para sustentar una acción moral, o las implicaciones de sustentar un marco epistémico principialista. El cuarteto debe abandonarse como dogma. El giro bioético supone una interpretación, no más profunda, pues en última instancia esta palabra es gratuita, nada dice. El giro debe procurar una interpretación responsable, o más imperativamente: una interpretación académicamente responsable. Si vamos a hablar de bioética como guía de las acciones técnicas del ser humano, entonces debemos ser rigurosos con el concepto. Nunca es suficiente recordar al viejo Aristóteles. Según el filósofo del Liceo, "es propio del hombre culto procurar alcanzar la exactitud en cada género de conocimiento, en el grado y medida de exactitud que la naturaleza del asunto a examinar permite.”(Ética a Nicómaco, I, p. 3). Aquí existe una orientación de una hermenéutica responsable, proveniente de una de las figuras más importantes de la filosofía clásica.

La responsabilidad de asumir un marco de referencia va más allá de simpatías emocionales. Asumir un cuerpo de conocimiento implica asumir una moralidad, una política, una ideología. Y ninguna de estas posiciones pasa inadvertidas para la comunidad humana. Asumir una ética marxista o liberal es asumir una práctica política, una práctica moral, una práctica económica. Por eso es atinente el consejo del viejo filósofo: procurar alcanzar la exactitud en el conocimiento que estamos asumiendo. Si vamos a asumir la bioética como marco de referencia para la acción, debemos saber que los conceptos que edifican sus bases epistémicas son fundamentales para determinar el tipo de conocimiento con el que vamos a referirnos a la realidad social humana.

Entonces, reconceptualizar la bioética quiere decir, en primera instancia, abandonar su simplicidad reduccionista y su vaguedad conceptual. Implica incorporar a su marco conceptual una serie de variables que amplían 
su marco de acción. Implica también armarla de mayor rigurosidad, pues la vaguedad condiciona su legitimidad como conocimiento. Reconceptualizar la bioética implica, pues, determinar su verdadero campo de acción, sus bases axiológicas y epistemológicas, su marco metodológico, su legitimidad profesional o académica. ¿No es suficiente? Por supuesto que no. La bioética también es una tarea que se tiene por delante.

\section{Una tarea por delante...}

La Bioética no se agota en cuatro principios. Los llamados cuatro principios de la bioética no responden a la cantidad de problemas que enfrenta el ser humano. Pocas disciplinas se estudian para resolver problemas sociales concretamente. El trabajo social es una de estas profesiones. Cada una ofrece a la comunidad humana un poco de sí para resolver problemas sociales. Este es el motivo por el cual el ingenuo reduccionismo bioético debe abandonarse siempre que se quiera desarrollar una bioética global. La bioética principialista es una bioética clínica, biomédica, pero en modo alguna la Bioética.

Considerar que la bioética puede desarrollar su campo de acción a partir de cuatro principios rectores es una ingenuidad. Los problemas que enfrenta el ser humano son complejos como para considerar que cuatro principios éticos pueden dar respuesta a un análisis profundo. De hecho la ética es una orientación teórica. Pero en sentido estricto, pocos problemas humanos se resuelven a la luz de categorías éticas en sentido histórico. Es decir, Kant, Aristóteles, Mill, son puntos de referencia para pensar la ética. Considerar que sus puntos de vista éticos dan respuesta a los problemas morales que enfrentamos a diario es poco razonable. De la misma la forma la bioética no puede concebirse como si cuatro principios orientaran toda la investigación hospitalaria, o que a partir de una bioética hospitalaria, puedan abordarse todos los problemas sociales del ser humano.

Cuando se habla de rigurosidad conceptual se habla de responsabilidad académica. Es un tipo de responsabilidad que supone implicaciones morales, éticas, políticas, científicas, en una palabra, implicaciones profesionales. Resulta ingenuo concebir una bioética protocolar en la que a través de una lista de chequeo se determina si se respeta o no el principio de autonomía, 
como si un formulario que hace referencia a cuatros principios de la bioética, es bioética en sentido estricto.

Ser objetivos, bioéticamente hablando, demanda abandonar el dogmatismo bioético, es decir, considerar que la bioética se compone de cuatro principios. Eso demanda a la vez realizar un riguroso examen sobre los marcos epistémicos que están sustentando lo que recibimos por conocimiento objetivo, al igual que los marcos axiológicos desde los cuales asumimos los valores que orientan nuestra vida social. Un concepto no causa indigestión, no causa diarrea. Pero sí causa otro tipo de males: no es lo mismo decir en un almuerzo: hoy me convertí al apartheid, que decir, hoy me convertí al protestantismo; o bien decir: me hecho trotskista, que decir, me hecho neoliberal. Asumir conceptos éticos, morales, religiosos, políticos, bioéticos, tiene implicaciones igualmente éticas, morales, etc.

Para ir más allá del principialismo se debe reconceptualizar el término de bioética. No necesita reconceptualizar la bioética aquel profesional dogmático, conformista con su entorno intelectual. Cuando la bioética se vuelve parte de un protocolo burocrático, cuando se vuelve parte de una justificación para tener dietas y presupuestos, cuando se vuelve parte de un gancho para tener reconocimiento académico, cuando se vuelve parte de una estrategia para tener reconocimiento público...Cuando la bioética se vuelve todo esto, no hace falta ir más allá del principialismo ingenuo y dogmático. Por el contrario, cuando se desea elevar la bioética como disciplina, y a partir de ella realizar cambios en el entorno social, entonces hace falta reconceptualizarla. La bioética sigue en curso, no es una disciplina madura. Apenas ofrece atisbos epistémicos y metodológicos.

\section{Referencias}

Aristóteles (2001). Ética a Nicómaco. Madrid: Mestas

Beas Franco, J. et al (2008). Enseñar a pensar para aprender mejor. Santiago: Ediciones de la Universidad Católica de Chile

Beauchamp, T. y Childress, J. (1999). Principios de ética biomédica. Barcelona: Masson.

Buchanan, A. y Brock, D. (2009). Decidir por otros. Ética de la toma de decisiones subrogada. México: FCE

Bunge, M. (2005). Buscar la filosofía en las ciencias sociales. México: Siglo XXI 
Carranza Carnicero, J. y Escudero Sanz, A. (1999). Teorías psicológicas del desarrollo moral: status teórico y alcance práctico. En Esteban Pérez Delgado y María Vicenta Mestré Escrivá, M. (coords). Psicología moral y crecimiento personal. Barcelona: Ariel.

Casado, D. R. A., y Seoane, J. A. (2008). Bioética para legos: una introducción a la ética asistencial. México: Plaza y Valdés.

Casanova Ríspoli, E. (2008). La caducidad del principialismo. II Congreso Internacional, UNESCO. Ponencia.

Comités de Bioética (2006). Caja Costarricense de Seguro Social. Centro de Desarrollo Estratégico e Información en Salud y Seguridad Social (CENDEISSS). Área de Bioética. Recuperado de http://www.cendeisss.sa.cr

Comités de bioética en la CCSS (s.f). Caja Costarricense de Seguro Social. Centro de Desarrollo Estratégico e Información en Salud y Seguridad Social. Área de Bioética. Recuperado de http://www.cendeisss.sa.cr

Dancy, Jonathan (1993). Introducción a la epistemología contemporánea (Traducido por José Luis Prades Celma). Madrid: Tecnos.

De Alba, A. (2014). Hermenéutica, metáfora y conversación. En Beuchot Puente, M. y Pontón Ramos, C. (coords). Cultura, educación y hermenéutica (pp. 95-109). México: UNAM

Feito Grande, L. (2010). Aspectos filosóficos de la relación entre las mujeres y la bioética: hacia una perspectiva global. En Javier de la Torre (ed). Mujer, mujeres y bioética. Madrid: Universidad de Comillas

Garrafa, V. y Osório de Azambuja, L. (2009) Epistemología de la bioética. Enfoque latino-americano. Revista Colombiana de Bioética. 4 (1), 73-92

Garrafa, V., Kottow, M., Saada, A. (2005). Estatuto epistemológico de la bioética. México: UNESCO.

Gracia, D. (2000). Fundamentación y enseñanza de la bioética. Bogotá: El Búho

Informe Belmont Principios y guías éticos para la protección de los sujetos humanos de investigación (2003). Centro de Documentación de Bioética. Universidad de Navarra. Recuperado de http://www.unav.es/cdb/usotbelmont.html

Langbein, K, y Ehgartner, B. (2002). Las traiciones de la medicina. Negocios sucios y corrupción en el sistema sanitario. Barcelona: Robinbook

Lifshitz, A. (2002). El significado actual del "primum no nocere". Facultad de Medicina de la UNAM. Recuperado de http://www.facmed.unam.mx/sms/seam2k1/2002/ponencia_jul_2k2.html

López de la Vieja, M. T. (2002). Los principios morales. Revista de Filosofía de la Universidad de Costa Rica 40 (102), 13-19

Manual de funcionamiento interno del Comité de Bioética Clínica y en Gestión de la Caja Costarricense de Seguro Social (2008). Caja Costarricense de Seguro social. Hospital Dr. Max Peralta, Cartago. Comité Local de Bioética Clínica y en Gestión

Navarro, M. (2009). Interpretar y argumentar. Madrid: Plaza y Valdez. http://dx.doi. org/10.5211/9788492751594

Pardo, A. (2010). Cuestiones básicas de bioética. Madrid: Rialp.

Pérez Soto, C. (1998). Sobre el concepto histórico de la ciencia. Santiago de Chile: Universidad ARCIS 
Pinto Bustamante, B. J. (2010) Bioética, crítica y sociedad más allá del principialismo. Universidad El Bosque. Revista Colombiana de Bioética. 5 (1), 73-84

Requena Meana, P. (2005). El principialismo y la casuística como modelos de bioética clínica. Tesis de doctorado. Pontificia Universidad de Santa Cruz. Facultad de Teología.

Roa, A. (1998). Ética y bioética. Santiago-Chile: Andrés Bello

Villarroel, R. (2000). Bioética y hermenéutica. Acta Bioethica, 6 (1). Recuperado de http://www.scielo.cl/pdf/abioeth/v6n1/art11.pdf http://dx.doi.org/10.4067/ S1726-569X2000000100011 